\title{
Non-Neoplastic Hepatobiliary Disorder
}

National Cancer Institute

\section{Source}

National Cancer Institute. Non-Neoplastic Hepatobiliary Disorder. NCI Thesaurus. Code C96853.

A non-neoplastic disorder that affects the liver, bile ducts, and gallbladder. Representative examples include hepatitis, cirrhosis, cholangitis, and cholecystitis. 